\title{
Multipurpose Management in the Tasks of Strategic Planning
}

\section{Vladimir Tsybatov}

\author{
Samara State University of Economics, Doctor of Economics, Professor; Email: tva82@yandex.ru
}

\section{Doi:10.5901/mjss.2015.v6n6s3p336}

\section{Abstract}

The study suggests models, methods and systems of multipurpose management in strategic plannig for regional socioeconomic development. Special attention is paid to the model of activities of a region (a subject of the Russian Federation), which reconstitutes the dynamics of socio-economic processes, and to the methods of multipurpose management that form managerial decisions on the model of a region. The model of the region's activities is developed in the class of Computable General Equilibrium (CGE) models that view development of an economy as a result of activities of the economic agents. The economy of the region is divided into economic agents according to the boundaries of sections and subsections of the Russian Classification of Economic Activities (OKVED) to which the household sector, agent "governmental bodies", agent "external environment" and agent "invisible hand of the market", responsible for the balance of supply and demand on the product markets (totally 33 agents), were added. It is shown that the most important task of strategic management is evaluation of attainability of the stated goals, which belongs to the class of mega-dimensional multipurpose management tasks. The author suggests a matrix method of solving this task for dozens of goals, hundreds of managing variables and long-term forecasting horizons. The material of formation of the information base of the region's model is publicly available regional statistics and reports of different ministries and departments subjected to pre-verification, completion and correction. The developed methods, models and information technologies of regional strategizing were successfully probated while forming the strategies of Altai Krai, Krasnoyarsk Krai and Samara Oblast. The main components of these technologies formed the basis of creation of the series of automated systems and complexes that are used in a number of subjects of the Russian Federation.

Keywords: strategic planning for regional socio-economic development, CGE models, multipurpose management, evaluation of attainability of the stated goals.

\section{Introduction}

The most important task of strategic planning for regional development is evaluation of attainability of the stated goals because the results of this task show whether or not the strategy that is being developed has a chance to be implemented. This task became particularly relevant after the adoption of the federal law of the Russian Federation "On Strategic Planning in the Russian Federation" (the law "On Strategic Planning in the Russian Federation", 2014). However, in practice this task has not yet been provided with necessary scientific and technical support. Consequently, development of methods and systems for evaluation of attainability of goals in strategic planning for regional development is an up-to-date and relevant problem, which stipulated the choice of the theme of the present study.

To evaluate attainability of goals stated in the strategy for regional development, the following components are needed:

1 - economic-mathematical model of large dimensionality which reproduces socio-economic activities of the region;

2 - methodical and software tools which make it possible to solve multipurpose management tasks of large dimensionality on the model of the region;

Recent decades of regional modeling are marked by the increase in importance of methods and models that view an economy as a result of purposeful activity of economic agents. (Bakhtizin, 2008). These methods are better than others when it comes to evaluation of long-term prospects of the economy and the results of economic policy options. In economic theory, economic agents are understood as entities engaged in economic activities on the basis of their own decisions (Pospelov, 2001). In macro-models, an economic agent is a collective entity, uniting elementary entities performing similar roles in the economy. Usually this is a sector of the economy. Modern macroeconomic models coordinate description of behavior of the economic agents on the target trajectory within the framework of balance of supply and demand on the modeled markets. The most successful models of regional economy are known in scientific literature as Computable General Equilibrium models (CGE models). These are the systems of dynamic equations, 
solution to which is a general equilibrium of supply and demand on the markets of goods and services considered in the model (Wickens, 2008; Dixon Peter and Maureen Rimmer, 2002). Russia's first CGE model - RUSEC - was developed in 1997 by Academician Makarov V.L. (Makarov, 1999). Other important Russian models are presented in (Makarov, Bakhtizin, Sulakshin, 2007). Depending on equilibrium model used in practice, CGE models can be divided into the following groups:

- CGE models using Leontief's interbranch balance to ensure general equilibrium (Taylor L., 1990);

- CGE models of Walras type, a practical implementation of the well-known model of general economic equilibrium of Walras (Feltenstein A., Shah A., 1995; Markusen J., Rutherford T., Hunter L., 1995);

- CGE models using the matrix of financial flows, known in the literature as Social Accounting Matrix (SAM). This matrix shows the balance of revenues and expenditures of the economic agents including financial flows of end users and governmental bodies (Pyatt and Round, 1985). In fact, it is an extension of the table of interbranch balance in value form.

The first group of models works successfully with goods and services for intermediate consumption. The second group considers wider range of goods and services. The third group takes into consideration financial markets, taxes, export and import operations. But a lot of important goods and services are left outside the used balance schemes. It is necessary to have the so-called "balance of balances" which will unite intermediate consumtion, finance, investments, consumer goods and services, labor and government services. To construct such a balance, it is suggested using the product and sector balance (PSB) which, unlike interbranch balance, describes not the interbranch ties but the ties between markets and sectors of the economy (Tsybatov, 2013). The methodological basis of PSB consists of tables of the System of National Accounts - 2008 which describe the existing resources and their use (The System of National Accounts 2008, 2012; Tables 14.12-14.14). In the suggested model, the economy of a subject of the Russian Federation (RF) is divided into 33 economic agents according to the boundaries of sections and subsections of the OKVED (Methodological Guidelines on Statistics, 2006) and activities of the agents are grouped into sectors of economy in accordance with the products produced.

The developed model of a region is used to study attainability of goals in strategic planning for regional development. The task of evaluation of attainability of goals refers to the group of mega-dimensional tasks. The procedure of its solution is a targeted sequence of tasks of scenario forecasting where scenarios of development, generated by some search algorithms, are calculated on the model of the region. The complexity of solution of the problem depends on dimensionality of the vector of scenario parameters, the number of tests on the range of regulation, the number of points on the horizon of forecasting and the complexity of a single scenario forecasting task. Gradient methods of finding the best scenario with the use of procedures of experiment planning (Gill, Murray, Wright, 1985) as well as search procedures based on Newton's method (Volkov, 2003) very quickly run into the "curse of dimensionality". These search methods are not suitable for long-term horizons of forecasting and scenarios of real dimensionality. It is necessary to find a method of solving that would overcome the "curse of dimensionality" and would allow solving inverse tasks for dozens of goals, hundreds of variables and deep horizons of forecasting. Our study proposes such a method.

On the basis of the created models and methods, the author has elaborated multi-purpose management methodology which was then developed into information technology. This technology has been successfully tested in a number of subjects of the Russian Federation when working out regional development strategies.

\section{The Results of the Research}

\subsection{The suggested conceptual scheme of the system of strategizing}

Fig. 1 is a conceptual scheme of the system of strategizing designed for study of strategies for regional development. The system performs the function of forecasting of indicators of socio-economic development of a subject of the Russian Federation, strategic goal-setting and multipurpose management (evaluating attainability of goals and searching for best scenarios in the context of the stated goals). 


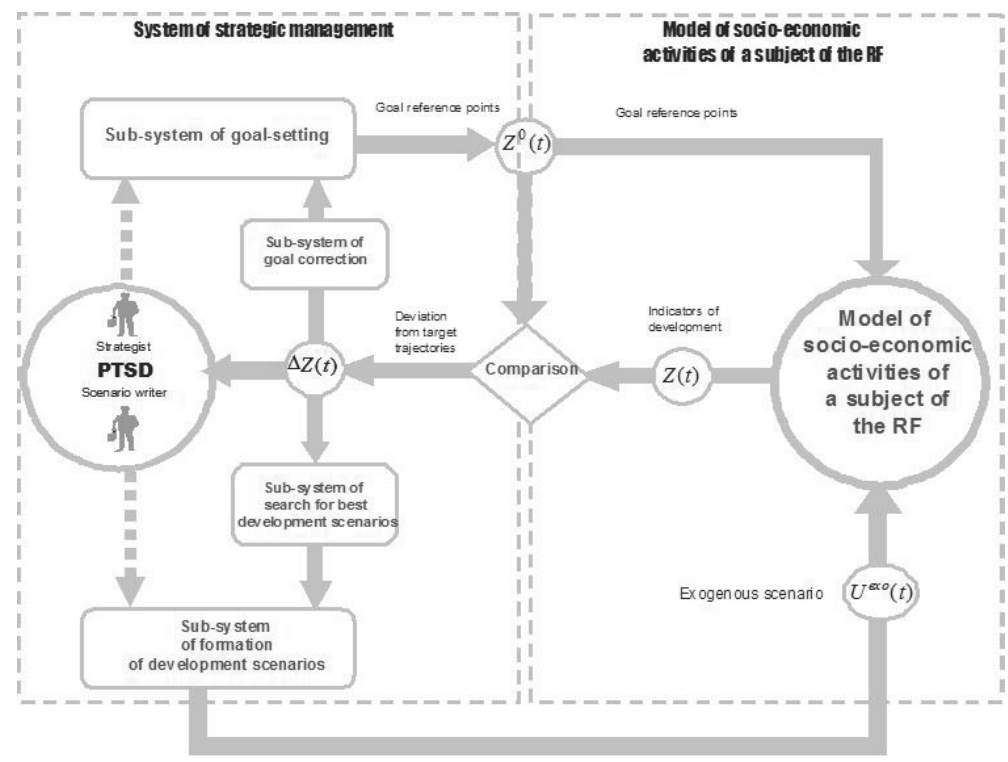

Figure 1. Conceptual Scheme of the System of Regional Strategizing.

The system of strategizing includes:

- the model of activities of a region showing the dynamics of socio-economic processes;

- the system of strategic management forming and probating managerial decisions on the model of the region.

The strategic management system is run by persons taking strategic decisions (PTSD). These are individuals performing forecasting and strategy development. Their role is crucial because it is their goals, efforts and interests that form the process of strategizing. They set targets and scenarios, form criteria of selection of the best managerial decisions.

\subsection{The model of socio-economic activities of the subject of the Russian Federation}

The model of activities of a region is developed in the class of computable general equilibrium (CGE) models. The following tasks were solved while constructing the model:

1 - division of the region's economy into in a variety of economic agents;

2 - development of conventional product models;

3 - development of production functions of the economic agents;

4 - ensuring of dynamic equilibrium on the conventional product markets;

5 - formation of information base of the model using publicly available regional statistics.

The region's economy is divided into economic agents according to the boundaries of sections and subsections of the OKVED $(A 1, A 2, B, C A, C B, D A, D B, \ldots, D N, E, F, \ldots, N, O)$ with the addition of the agent "household sector", agent "governmental bodies ", agent "external environment" and agent "invisible hand of the market" responsible for balance of supply and demand on the markets for goods and factors of production (totally 33 economic agents). Economic agents related to the real sector of the economy seek to reach sustainable growth while maintaining rate of return within acceptable limits. They manage their resources according to their own plans, the state of the production factors and external environment. Economic agents related to the sector of non-market services (sections $L, M, N$ of the OKVED) provide mainly non-market services. Instead of payment for the services, these agents receive transfers from budgets of all levels and non-budgetary funds. Economic agent "governmental bodies" is a collective managing center consisting of the region's authorities and the federal government which has its own interests in the region. This agent is guided by the goals set out in the region's development strategy which express balanced interests of the federal government and the regional community. To achieve these goals, the agent generates budgets of all levels and provides free collective and 
individual services on governing, military security and social security. Economic agent "household sector" reproduces population and the labor force. The agent provides labor services, manages employment in the sphere of economic activities and distribution of incomes derived from labor activities and in the form of transfers from the state. Economic agent $W$ "external environment" manages external supply and demand, external investments and prices on foreign raw materials.

The model description of an economic agent includes description of its production function, resources (natural, labor, capital and financial resources) and its behavior within the framework of the reproduction process (Fig. 2).

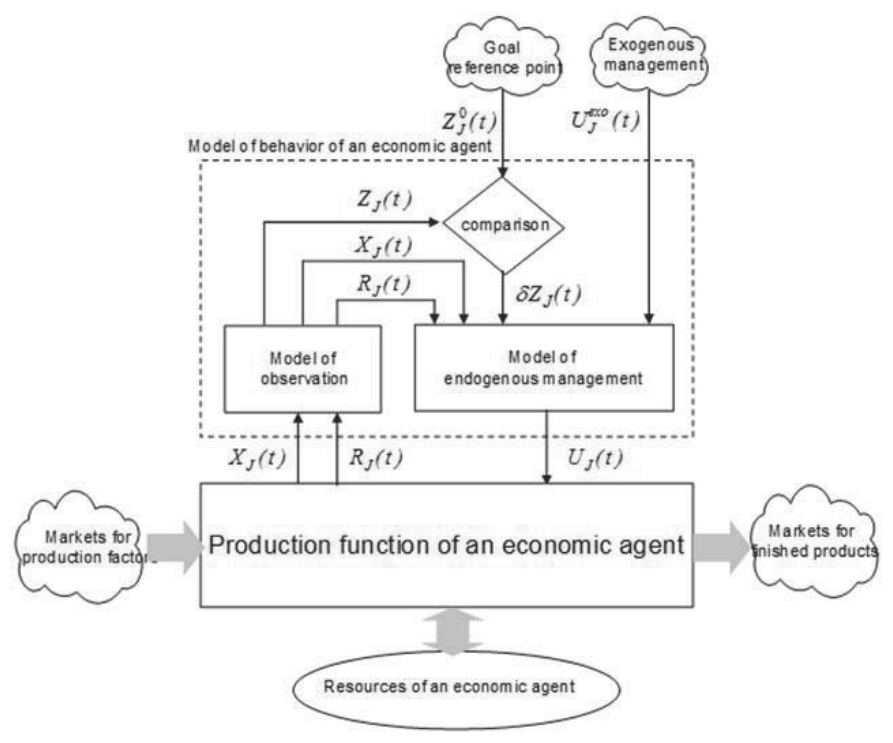

Figure 2. The Model of an Economic Agent.

It is believed that economic agents produce one or more conventional products from the conventional base set that are sold within the region or exported. At the same time, the necessary products from both within the region and beyond it are purchased. The model uses the following line of conventional products which is based on the logic of the reproduction process:

- $\quad$ intermediate goods and services (product $m$ );

- investment goods and services (product $k$ );

- consumer goods and services (product $c$ );

- government services (product $g$ );

- labor services (product $h$ ).

For the purposes of a more detailed economic modeling, basic conventional products can be decomposed to the desired depth taking into account the existing groups of goods and services. For example, "intermediate goods and services" can be divided into: raw materials; energy resources; infrastructure services; financial intermediation services.

Using the terminology of the SNA (System of National Accounts, 2008, 2012), we assume that every economic agent (section or subsection of the regional economy) consists of one or more joint establishments, each of which produces one conventional product. The use of establishment as a unit of classification allows to divide integrated establishments according to conventional products they produce. Table 1 shows distribution of sections of the economy according to establishments producing conventional products. Numbers indicate the proportion of establishments in gross output of the relevant sections (subsections) of the economy. 
Table 1. Distribution of Gross Output of the Sections of the Economy by conventional products (example).

\begin{tabular}{|c|c|c|c|c|c|c|}
\hline \multirow{2}{*}{ № } & \multirow{2}{*}{ Section/subsection of the economic activities (economic agents) } & \multicolumn{5}{|c|}{ Conventional products } \\
\hline & & $M$ & K & $C$ & $g$ & $h$ \\
\hline & Section A: Agriculture, hunting and forestry & & & & & \\
\hline 1 & Sub-section A-01: Agriculture, hunting and related service activities & $60 \%$ & & $40 \%$ & & \\
\hline 2 & Sub-section A-02: Forestry and related service activities & $100 \%$ & & & & \\
\hline 3 & Section B: Fishing & $50 \%$ & & $50 \%$ & & \\
\hline & Section C: Mining and quarrying & & & & & \\
\hline 4 & Sub-section CA: Mining and quarrying of energy producing materials & $100 \%$ & & & & \\
\hline 5 & Sub-section CB: Mining and quarrying except energy producing materials & $100 \%$ & & & & \\
\hline & Section D: Manufacturing & & & & & \\
\hline 6 & Sub-section DA: Manufacture of food products, beverages and tobacco & & & $100 \%$ & & \\
\hline & 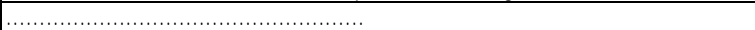 & & & & & \\
\hline 16 & Sub-section DK: Manufacture of machinery and equipment not elsewhere classified & $33 \%$ & $45 \%$ & $22 \%$ & & \\
\hline 17 & Sub-section DL: Manufacture of electrical and optical equipment & $19 \%$ & $63 \%$ & $18 \%$ & & \\
\hline 18 & Sub-section DM: Manufacture of means of transport and equipment & $18 \%$ & $17 \%$ & $65 \%$ & & \\
\hline 19 & Sub-section DN: Manufacturing not elsewhere classified & $100 \%$ & & & & \\
\hline 20 & Section E: Electricity, gas and water Supply & $72 \%$ & & $28 \%$ & & \\
\hline 21 & Section F: Construction & & $100 \%$ & & & \\
\hline 22 & Section G: Wholesale and retail trade . & $57 \%$ & & $43 \%$ & & \\
\hline 23 & Section H: Hotels and restaurants & & & $100 \%$ & & \\
\hline 24 & Section I: Transport and communications & $68 \%$ & & $32 \%$ & & \\
\hline 25 & Section J: Financial intermediation & $90 \%$ & & $10 \%$ & & \\
\hline 26 & Section K: Real estate, renting and business activities ... & $68 \%$ & & $32 \%$ & & \\
\hline 27 & Section L: Public administration and defence... & & & & $100 \%$ & \\
\hline 28 & Section M: Education & & & $29 \%$ & $71 \%$ & \\
\hline 29 & Section N: Health and social work & & & $19 \%$ & $81 \%$ & \\
\hline 30 & Section 0: Other community, social and personal service activities & & & $100 \%$ & & \\
\hline 31 & Sector H: Households & & & & & $100 \%$ \\
\hline
\end{tabular}

Let us mark the set of products produced by the ${ }^{J}$-agent $\left({ }^{J \in D_{J}}\right)$ :

$$
s_{J}=\left[s_{m, J}, s_{k, J}, s_{c, J}, s_{g, J}, s_{h, J}\right]^{T} \text {, }
$$

where $s_{i, J}$ is the quantity of $i$ - product $\left({ }^{i=m, k, c, g, h}\right)$ produced by the agent $J$ per year. Set $D_{J}$ includes symbol names of agents (Table1), which in some cases will be referred to by their number: $1,2, \ldots, 33$.

When producing a certain set of goods ${ }^{s_{J}}$, the agent purchases basic products on the corresponding markets for goods and services in quantities $x_{J}=\left[x_{m, J}, x_{k, J}, x_{c, J}, x_{g, J}, x_{h, J}\right]^{T}$, where

$x_{J}=A_{J} s_{J}$,

Here $A_{J}=\left\|a_{i, j}^{(J)}\right\|$ is a technological matrix, each element ${ }^{a_{i, j}^{(J)}}$ of which shows the quantity of product $i$ purchased for the production of product ${ }^{j}$ from the set of products $s_{J}$. (Fig. 3):

Production activity of the agent will be described by the following bi-directional generalized production function

a) movement of products - from factors of production to finished products (thick lines in the Figure 3):

$s_{J}(t)=\min \left\{s_{J}^{\text {plan }}(t), s_{J}^{\text {pot }}(t), s_{J}^{\text {dem }}(t)+\Delta s_{J}(t)\right\}$;

$x_{J}(t)=A_{J}(t) s_{J}(t)$;

б) movement of money - from profit from the products to payment for the factors of production (thin lines in the Figure 3):

$$
\begin{aligned}
& d_{E, J}(t)=s_{J}(t) \otimes P_{J}(t) ; \\
& d_{J}(t)=x_{J}(t) \otimes P(t) .
\end{aligned}
$$

where (3) is supply of the agent $J$ on the corresponding markets in material form (in natural units);

(4) - purchased factors of production in material form (demand from the agent for the production factors in material form);

(5) - money from the products sold;

(6) - effective demand from the agent for the necessary intermediate products and production factors (demand 
from the agent for the production factors in money form);

$s_{J}^{\text {plan }}(t)=s_{J}^{\text {plan }}\left(U_{J}, t\right)$ is the column vector of planned output of the agent $J$ («what the agent wants )»);

$s_{J}^{p o t}(t)$ is potential output of the agent ${ }^{J}$ calculated according to the main production factors and taking into account budget limits («what the agent is capable of doing»);

$x_{J}(t)=\left[x_{m, J}(t), x_{k, J}(t), x_{c, J}(t), x_{g, J}(t), x_{h, J}(t)\right]^{T}$ is the column vector of products of the economy used by the agent for production activities (2);

$s_{J}^{d e m}(t)$ is the vector of demand for products produced by the agent $J$ from other economic agents including nonresidents («what the agent is to do »);

$\Delta s_{J}(t)$ is the vector of growth of the stock of products produced by the agent $J$;

$d_{E, J}(t)$ is the effective demand for the products of the agent $J$;

$d_{J}(t)=\left[d_{m, J}(t), d_{k, J}(t), d_{c, J}(t), d_{g, J(t)}, d_{h, J}(t)\right]^{T}$ is the vector of effective demand from the agent for products including intermediate goods and services $\left({ }^{d_{m, J}}\right)$, investment goods and services $\left({ }^{d_{k, J}}\right)$, consumer goods and services

$\left({ }^{d_{c, J}}\right)$, labor services $\left({ }^{d_{h, J}}\right)$, government services $\left({ }^{d_{g, J}}\right)$;

$\otimes$ - element-wise matrix multiplication symbol;

$P_{J}(t)=\left[p_{m, J}(t), p_{k, J}(t), p_{c, J}(t), p_{g, J}(t), p_{h, J}(t)\right]^{T}$ - prices established by the agent $J$ for its products;

$P(t)=\left[p_{m}(t), p_{k}(t), p_{c}(t), p_{g}(t), p_{h}(t)\right]^{T}$ is the vector of average product prices on the markets.

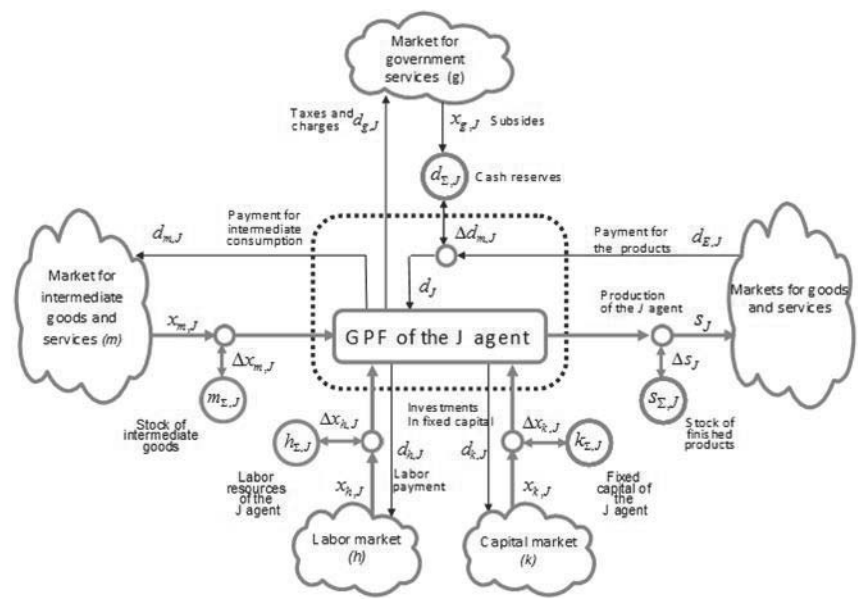

Figure 3. Generalized Production Function of the Agent

In the course of its activities, an economic agent manages desired output $s_{J}^{\text {plan }}(t)$ and parameters of the technological matrix $A_{J}(t)$ that defines norms of acquisition of intermediate goods, capital and labor to maintain the desired rate of production process. Norms of intermediate consumption can vary with changes in material and energy intensity of production. The norm of accumulation of capital depends on capital intensity of production but current investments are carried out on the basis of the need for replenishment of capital and cash reserves available to the agent. Norms of labor costs are determined by complexity of the products and may vary with changes in productivity. Norms are set exogenously. Current consumption of factors of production is determined by the norms of consumption and reserves. The vector of resources of the agent $J$ contains the following components (Fig. 3):

$R_{J}=\left[m_{\Sigma, J}, k_{\Sigma, J}, h_{\Sigma, J}, d_{\Sigma, J}, s_{\Sigma, J}\right]$,

where $m_{\Sigma, J}$ is the stock of intermediate products; ${ }_{\Sigma \Sigma, J}$ - stock of fixed capital; ${ }^{h_{\Sigma, J}}$ - available labor resources; 
$d_{\Sigma, J}$ - cash reserves; ${ }_{\Sigma, J}$ - the stock of unsold finished products. Figure 3: $\Delta x_{m, j}, \Delta x_{k, j}, \Delta x_{h, j}$ - the net increase in the stock of related products (inputs) used by the agent $J ; \Delta d_{J}$ - the net increase in cash reserves of the agent $J$. The dynamics of resources of the agent is described by the following equation:

$$
d R_{J}(t) / d t=R_{J}^{\text {in }}\left(R_{J}, X_{J}, t\right)-R_{J}^{\text {out }}\left(R_{J}, X_{J}, t\right) .
$$

Where $R_{J}^{\text {in }}(.){ }_{n} R_{J}^{\text {out }}($.) are the functions of growth and outflow of the resources of the economic agent;

$X_{J}(t)$ is the vector of parameters of the reproduction process (6) - (9).

On the basis of resources (7), the function of the potential output of the agent $s_{J}^{\text {pot }}(t)$ is formed (see. (3)) which is designed as a Leontief production function

$$
s_{J}^{\text {pot }}(t)=\min \left\{s_{J, k}^{\text {pot }}\left(A_{J}, k_{\Sigma, J}, t\right), s_{J, h}^{\text {pot }}\left(A_{J}, h_{\Sigma, J}, t\right)\right\},
$$

This function describes changes in the agent's output possibility frontier depending on the state of the main production factors (capital and labor factors) and norms of technological costs. Here $s_{J, k}^{p o t}\left(A_{J}, k_{\Sigma, J}, t\right)$ is potential output with the given fixed capital - the highest possible annual output with the given fixed assets on the assumption that the capital is sufficient to use the labor resources at the level of their potential; the function characterizes the technical capacity of the stock of capital; $s_{J, k}^{p o t}\left(A_{J}, h_{\Sigma, J}, t\right)$ is potential output with the given labor resources on the assumption that the capital is sufficient to use the labor resources at the level of their potential.

The model of behavior of an economic agent will be developed as a system of management that works in deviations (D.A. Novikov, A.G. Chkhartishvili, 2002). The basis of behavior of each economic agent ${ }^{J}$ where $J \in D_{J}$ is the target trajectories $Z_{J}^{0}(t)$ that orient its actions towards ensuring achievement of the goals (see. Fig. 2). Taking into account parameters of the environment $X_{J}(t), R_{J}(t)$, the observed trajectory of indicators $Z_{J}(t)$ and indicators' target values $Z_{J}^{0}(t)$, the agent $J$ forms permissible managing actions $U_{J}^{\text {end }}(t) \subset D_{U, J}^{\text {end }}(t), t \in[0, T]$ on the production process. These managing actions are obtained as a result of solving optimization task in which indicator's trajectories $Z_{J}(t)$ are as close as possible to ${ }^{Z_{J}^{0}}(t)$ (the deviations are minimized on the whole horizon):

$$
\begin{aligned}
& \min _{U_{J}^{\text {end }}(t) \subset D_{U, J}^{\text {end }}(t)}\left\{Q_{J}\left(Z_{J}, Z_{J}^{0}, t\right)\right\} ; \\
& Z_{J}(t)=M_{Z, J}\left(R_{J}, X_{J}, U_{J}^{\text {exo }}, U_{J}^{\text {end }}, t\right) .
\end{aligned}
$$

Where $Q_{J}$ is the total deviation;

$U_{J}^{e x o}$ is the vector of external (exogenous) managing parameters of the agent $J$ set, for example, by persons taking strategic decisions or other agents;

$D_{U, J}^{\text {end }}$ is the range of permissible values for the vector $U_{J}^{\text {end }}$ (technological, budget and institutional restrictions);

$M_{Z, J}($.$) is the model of observation of the agent J$ tracing the parameters of the environment $X(t), R_{J}(t)$ and forming current values of its target indicators $Z_{J}(t)$;

$T$ is the horizon of management (strategizing).

The architecture of the model of the subject of the Russian Federation is given in Fig. 4. The model is presented in the form of matrix of partial models of the economic agents. The columns of the matrix form the models of the economic agents (sections and subsections of the regional economy) and the rows of the matrix are "region-forming" models that join the corresponding resources of the region into a coherent whole. Financial resources are integrated into a single system which includes: consolidated regional accounts; income and expenditure accounts of the economic agents (sections and subsections of the economy); consolidated financial balance. To join the other resources, we use statistical balances of population, labor resources and fixed capital (Methodological Guidelines on Statistics, 1997).

General model of the reproduction process is obtained by combining generalized production functions (GPF) of the economic agents through the markets for produced and purchased products. In this model, an equilibrium on the markets is provided by the agent "invisible hand of the market" on the basis of the product-sector balance (PSB) which, unlike interbranch balance, describes not the interbranch relations but the relationship between markets and the corresponding sectors of the economy (Tsybatov V.A., 2013). Since the sectors generate bi-directional flows of products and paid demand for these products, it is necessary to form two balances to describe these flows: the PSB in material form (for conventional products) and PSB in value form. 


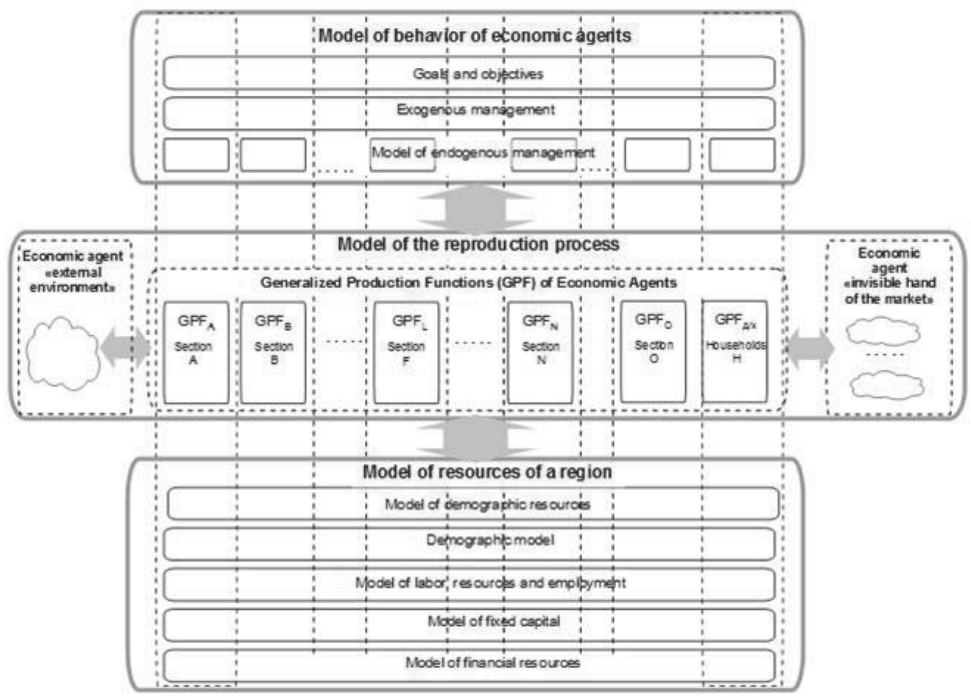

Figure 4. The Model of the Region as the Matrix of Partial Models

In practice, as a rule balances are drawn up only in value form. However, when making forecast calculations, this inevitably leads to serious distortions because of the differences in dynamics of product prices. Measuring the cost of the finished product in value form does not provide information on the extent of the production of finished products in natural units. This concerns in particular intermediate consumption as representation of intermediate goods in value form does not allow to model their consumption in the quantities needed for the production of certain products. In addition, all restrictions related to the potential output of sectors of the economy are of material nature. When modeling the flows in material form, laws of transformation and conservation of substance are at work. And when it comes to value form, budget restrictions take the place of these laws. That is why it is necessary to have the "balance of balances" which will combine demand and supply of products both in material and value form in a single balance scheme.

For the construction of the PSB, let us divide the economy into sectors that produce homogeneous products. It's easy to do this combining homogeneous establishments of the sections and subsections of the economy (Table 2). We obtain the following sectors: $\mathrm{M}$ is the sector producing intermediate products $\mathrm{m} ; \mathrm{K}$ is the capital sector producing investment products $\mathrm{k} ; \mathrm{C}$ is the consumer sector producing consumer products $\mathrm{c} ; \mathrm{G}$ is the sector of government services $\mathrm{g} ; \mathrm{H}$ is the household sector providing labor services $\mathrm{h}$.

Sectors are linked to each other and the outside world through the common product markets. Supply and demand on the market are balanced by export-import operations and the growth of stocks. We can make the following balance ratio for a conventional period (for example, a year) for the conventional product $i \quad\left({ }^{i=m, k, c, g, h}\right)$ :

$$
x_{i, M}+x_{i, K}+x_{i, C}+x_{i, G}+x_{i, H}=s_{i}-s_{i}^{\text {exp }}+s_{i}^{i m p}-\Delta s_{i} .
$$

Where: $x_{i, M}, x_{i, K}, x_{i, C}, x_{i, G}, x_{i, H}$ is purchasing of the product ${ }^{i}$ [natural units per year] in the sectors ${ }^{M, K, C, G, H}$ respectively; per year];

$S_{i}$ is the output of product $i$ in the region (output of the corresponding sector) in material form [units of product $i$

$s_{i}^{\exp }, s_{i}^{i m p}$ are the volumes of export and import of the product ${ }^{i}$ respectively;

$\Delta s_{i}$ is the growth of stock of the product $i$ in the region. 
Table 2. Division of Economy into Sectors.

\begin{tabular}{|c|c|c|c|c|c|c|}
\hline \multirow{2}{*}{ № } & \multirow{2}{*}{ Section/subsection of the economic activities (economic agents) } & \multicolumn{5}{|c|}{ Conventional products } \\
\hline & & $M$ & k & c & $g$ & $h$ \\
\hline & Section A: Agriculture, hunting and forestry & & & & & \\
\hline 1 & Sub-section A-01: Agriculture, hunting and related service activities & $V_{A 1, m}$ & & $V_{A 1, c}$ & & \\
\hline 2 & Sub-section A-02: Forestry and related service activities & $V_{A 2, m}$ & & & & \\
\hline 3 & Section B: Fishing & $V_{B, m}$ & & $V_{B, c}$ & & \\
\hline & Section C: Mining and quarrying & & & & & \\
\hline 4 & Sub-section CA: Mining and quarrying of energy producing materials & $V_{C A, m}$ & & & & \\
\hline 5 & Sub-section CB: Mining and quarrying except energy producing materials & $V_{C B, m}$ & & & & \\
\hline & Section D: Manufacturing & & & & & \\
\hline 6 & Sub-section DA: Manufacture of food products, beverages and tobacco & $V_{D A, m}$ & & $V_{D A, C}$ & & \\
\hline 16 & Sub-section DK: Manufacture of machinery and equipment not elsewhere classified & $V_{D K, m}$ & $V_{D K, K}$ & $V_{D K, C}$ & & \\
\hline 17 & Sub-section DL: Manufacture of electrical and optical equipment & $V_{D L, m}$ & $V D L, k$ & $V_{D L, C}$ & & \\
\hline 18 & Sub-section DM: Manufacture of means of transport and equipment & $V_{D M, m}$ & $V_{D M, K}$ & $V_{D M, C}$ & & \\
\hline 19 & Sub-section DN: Manufacturing not elsewhere classified & $V_{D N, m}$ & & & & \\
\hline 20 & Section E: Electricity, gas and water Supply & $V_{E, m}$ & & $V_{E, c}$ & & \\
\hline 21 & Section F: Construction & & $V_{F, k}$ & & & \\
\hline 22 & Section G: Wholesale and retail trade ... & $V_{G, m}$ & & $V_{G, c}$ & & \\
\hline 23 & Section $\mathrm{H}$ : Hotels and restaurants & & & $V_{H, c}$ & & \\
\hline 24 & Section I: Transport and communications & $V_{l, m}$ & & $V_{1, c}$ & & \\
\hline 25 & Section J: Financial intermediation & $V_{J, m}$ & & $V_{J, c}$ & & \\
\hline 26 & Section K: Real estate, renting and business activities ... & $V_{K, m}$ & & $V_{K, c}$ & & \\
\hline 27 & Section L: Public administration and defence... & & & & $V_{L, g}$ & \\
\hline 28 & Section M: Education & & & $V_{M, c}$ & $V_{M, g}$ & \\
\hline 29 & Section N: Health and social work & & & $V_{N, c}$ & $V_{N, g}$ & \\
\hline 30 & Section 0: Other community, social and personal service activities & & & $V_{0, c}$ & & \\
\hline 31 & Sector H: Households & & & & & $V_{H}$ \\
\hline
\end{tabular}

Value ${ }^{x_{i, I}}$ is calculated as a total purchase of the product $i$ by the establishments related to the sector $I$ $(I \in\{M, K, C, G, H\})$ :

$$
x_{i, I}=\sum_{j \in I} x_{i, j} \text {. }
$$

The output ${ }^{s_{i}}$ of the product $i$ in the region as total output of the establishments related to the sector $I$ $(I \in\{M, K, C, G, H\}): s_{i}=\sum_{j \in I} s_{i, j}$.

The calculation of the components $s_{i}^{\exp }$ and $\Delta s_{i}$ is the same. The import of the product $i$ is calculated for all establishments:

$$
s_{i}^{i m p}=\sum_{j \in M \cup K \cup C \cup G \cup H} s_{i, j}
$$

The left side of the balance equation (12) shows demand in material form for the product $i$ from the region's economy, and the right side - the product supply on the regional market, with possibilities of purchasing part of the products via import supplies, export of the sectors and changes in the stock of the unsold products being taken into account.

Let us write relative growth of stock of the product $i$ as $\delta x_{i}=\Delta s_{i} /\left(x_{i, M}+x_{i, K}+x_{i, C}+x_{i, G}+x_{i, H}\right)$. Then the indicator

$$
Q_{x}(t)=\sum_{i=m, k, c, g, h}\left|\delta x_{i}(t)\right|
$$

will characterize aggregated relative misbalance between demand and supply on the product markets calculated for the growth of stock in natural units $\left(t=t_{1}, t_{2}, \ldots, t_{T}\right)$. 

follows:

The PSB in value form for the product $i\left({ }^{i=m, k, c, g, h}\right)$, produced and purchased in the economy, will be written as

$$
d_{i, M}+d_{i, K}+d_{i, C}+d_{i, G}+d_{i, H}=v_{i}-v_{i}^{\text {exp }}+v_{i}^{i m p}-\Delta v_{i},
$$

In the left side of the balance the costs of the sectors ${ }^{M, K, C, G, H}$ on purchasing the product $i$ (efficient demand of the sectors) are shown and in the right side of the balance we see the supply of the product $i$. Here $v_{i}$ is the output of the product ${ }^{i}$ in the region (output of the corresponding sector) in value form [ruble/year]; $v_{i}^{\text {exp }}, v_{i}^{\text {imp }}$ are the volumes of export and import of the product $i$ in value form; $\Delta v_{i}$ is the net growth of stock of the product in value form [ruble/ year].

Similarly (13) the indicator

$$
Q_{d}(t)=\sum_{i=m, k, c, g, h}\left|\delta v_{i}(t)\right|
$$

is introduced which characterize aggregated relative misbalance on the product markets for the growth of the stock in value form $\left({ }^{t}=t_{1}, t_{2}, \ldots, t_{T}\right)$ where

$$
\delta v_{i}=\Delta v_{i} /\left(d_{i, M}+d_{i, K}+d_{i, C}+d_{i, G}+d_{i, H}\right) .
$$

The relationship between the material and value balances is realized through prices of the corresponding conventional products.

Let us study the dynamics of the reproduction process in the discreet time ${ }^{t=t_{0}, t_{1}, t_{2}, \ldots, t_{T}}$ with the constant step of one year. $T$ is the horizon of forecasting. In between we consider all the parameters of the model the same and we refer all the changes to the moment of transition of the model from one time point to another. The forecast trajectory will be a series of interrelated PSB in material (12) and value (14) forms constructed in compliance with the material and budget limits taking into account the movement of economic agents towards changing targets. To start the movement, it is necessary to build the PSB for the basic year $\left({ }^{t}=0\right)$. The elements of the value balance $(14)$ can be easily taken from the materials of the regional statistics for the basic year. To build the material balance (12) for the basic year it is necessary to make a transition from the element ${ }^{d_{i, J}(0)}$ showing the cost of purchasing the product $i$ by the sector ${ }^{J}$ to the element $x_{i, J}(0)$ characterizing this purchase in the units of the conventional product $i$. To do this, let us assume that in the basic year each sector $J$ made exactly 100 units of its production $\left({ }^{S}(0)=100\right.$ units $^{j}$ ) and then calculate basic internal prices of conventional products $p_{i}(0)$ and the coefficients of the technological matrix ${ }^{A_{J}}$.

\subsection{The Technology of Regional Strategizing}

The developed technology of regional strategizng includes the following stages:

1 - strategic goal-setting (determining region's development goals and objectives, formation of a list of strategic development indicators; specification of the target state of the region in the form of a target map);

2 - formation of the space of managerial decisions (identification of controls that can be used by economic agents to achieve the stated goals);

3 - situational forecasting in which for a given scenario trajectories of development indicators are calculated on the model of the region (a problem of the class "what if ...?");

4 - evaluation of attainability of the goals and formation of a path to the goal where the development scenario leading to the desired result is calculated according to the target map (the task of the class "what it is necessary to ...?");

5 - choosing scenario leading to the least, in terms of a given criterion, deviation from the target state.

Strategic goal-setting is the formation of the vector of target trajectories $Z_{S}^{0}(t)=\left[z_{S, 1}^{0}(t), z_{S, 2}^{0}(t), \ldots, z_{S, N}^{0}(t)\right]$ reflecting balanced interests of the federal government and the regional community. Vector $Z_{S}^{0}(t)$ contains target reference points for the activities of the economic agent "governmental bodies".

The formation of the space of managerial decisions means the construction of the general vector of managing variables $U=\left[U^{\text {exo }}, U^{\text {end }}\right]$ and establishment of boundaries for each regulator: $u_{i}^{\min } \leq u_{i} \leq u_{i}^{\max }, \forall i$. Here $U^{\text {end }}=\left[U_{1}^{\text {end }}, U_{2}^{\text {end }}, \ldots, U_{33}^{\text {end }}\right]$ is the general vector of endogenous management combining managment vectors of the economic agents. Vector $U^{\text {end }}$ is formed inside the model of the region, vector $U^{\text {exo }}$ comes to the model from outside. This vector is determined by persons taking strategic decisions or formed by the system of strategic management (Figure1). 
Situational forecasting is a form of forecasting of possible ways of regional development where according to the principle "what if" and given endogenous development scenario $U^{e x o}(t)$, the trajectories of the target indicators of the strategic level $Z_{S}(t)$ are calculated on the model of the region for the forecasting horizon $t_{1}, t_{2}, \ldots, t_{T}$ :

$$
Z_{S}(t)=M_{Z}\left(R, X, U^{\text {exo }}, U^{\text {end }(o p t)}, t\right) \text {. }
$$

The vector of the parameters

$$
U^{\text {end }(o p t)}(t)=\left[U_{1}^{\text {end }(o p t)}, U_{2}^{\text {end }(o p t)}, \ldots, U_{33}^{\text {end }(o p t)}\right] \text {, }
$$

included in the model (17) is a solution to the system of the optimization tasks of endogenous management (10) (11), solved for all the economic agents $J=1,2, \ldots, 33$. These tasks must be solved simultaneously with the tasks of ensuring balance on the markets for conventional products:

$$
\begin{aligned}
& \min _{U^{\text {end }}\left(t_{1}\right), U^{\text {end }}\left(t_{2}\right), \ldots, U^{\text {end }}\left(t_{T}\right)} \sum_{k=1}^{T} Q_{x}\left(U^{\text {exo }}, U^{\text {end }}, t_{k}\right) \\
& \min _{U^{\text {end }}\left(t_{1}\right), U^{\text {end }}\left(t_{2}\right), \ldots, U^{\text {end }}\left(t_{T}\right)} \sum_{k=1}^{T} Q_{s}\left(U^{\text {exo }}, U^{\text {end }}, t_{k}\right)
\end{aligned} ;
$$

Here the task (19) is to eliminate total misbalance (13) on the markets for conventional products, expressed in natural units, and the task (20) is to eliminate total market misbalance (15) expressed in value terms.

In strategic planning, it is necessary to choose the management $U^{\text {exo }}(t)$ which provides the least deviation from the strategic goals $Z_{S}^{0}(t)$. Evaluation of attainability of strategic goals is a major challenge since the results of this task make clear whether the strategy in question has a chance to be implemented or not. The peculiarity of the task lies in the fact that the goals, as a rule, tend to be contradictory, and ensuring of their achievement by the totality of the target indicators is mathematically unsolvable. To form a compromise solution, the criterion $\Phi($.$) is introduced which$ characterizes general "dissatisfaction" because of the deviation of the indicator vector $Z_{S}(t)$ from the set target trajectories $Z_{S}^{0}(t)$. And the task of attainability of the goals means solving the task of optimization: "to find a permissible scenario of economic development $U^{\text {exo }}(t) \subset D_{U}^{\text {exo }}(t)$, minimizing general "dissatisfaction" from failure of the vector $Z_{S}(t)$ (17) to reach the set target values $Z_{S}^{0}(t), t=t_{1}, t_{2}, \ldots, t_{T}$ ":

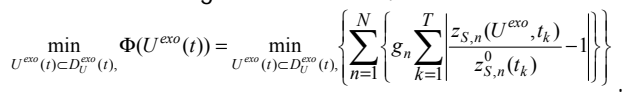

Content-wise, the task (21) is inverse to the task of direct prediction (17) - (20). The procedure of solving the task (21) is reduced to the targeted sequence of the tasks (17) - (20) when on the model $M_{Z}($.$) management vectors U^{\text {exo }}(t)$, generated by some algorithm, are tried out. The task (21) refers to the class of mega-dimensional multipurpose management tasks. The complexity of its solution depends on the dimensionality of the vector of scenario parameters $U^{e x o}=\left[u_{1}^{e x o}, u_{2}^{e x o}, \ldots, u_{L}^{e x o}\right]$, the number of points on the forecasting horizon $T$ and the complexity ${ }^{a_{0}}$ of the single solution of the task (17) - (20). The author developed a matrix method of search that allows to solve multi-purpose tasks of the class (21) for dozens of goals, hundreds of managing variables and deep forecasting horizons in reasonable time. The solver developed on its basis forms scenarios in which the target indicators are maximally close to the set goals taking into account the importance of these indicators (weights $g_{i}$ ) and restrictions on managing actions. The search for the best scenario on the model of the region when the number of goals $N=50$, the number of regulators $L=150$ and the horizon of $T=20$ years takes 20 minutes for a PC of average power.

The method includes the following stages:

Preliminary conditions. Instead of the vector $U(t)=\left[U^{\text {exo }}(t) ; U^{\text {end }}(t)\right]$ we use the following vector:

$$
U(t)=\left[U^{\text {exo }(0)}(t) \otimes K^{\text {exo }}(t) ; U^{\text {end }(0)}(t) \otimes K^{\text {end }}(t) \otimes K^{X}(t)\right],
$$

where $U^{\operatorname{exo}(0)}(t)$ is the initial approximation of the exogenous scenario; $U^{\text {end }(0)}(t)$ is the initial approximation of the endogenous management; $K^{\text {exo }}(t), K^{\text {end }}(t), K^{X}(t)$ are the correction vectors. The task (21) is solved for the vector $K^{\text {exo }}(t)$ , the task (18) is solved for the vector $K^{\text {end }}(t)$ and the task of ensuring the balance on the markets for conventional products (19)-(20) is solved for the vector ${ }^{K^{X}(t)}$.

Let us present the management vector (22) like this: 
$U(t)=\left[U^{(0)}(t) \otimes K(t)\right], t_{k}=t_{1}, t_{2}, \ldots, t_{T}$.

Here $U^{(0)}$ is the initial approximation of the general management vector (combined $U^{\text {exo( }(0)}$ and $U^{\text {end }(0)}$ ); ${ }^{K(t)}$ is the general orrection vector (combined vectors $K^{\text {exo }}(t), K^{\text {end }}(t)$ and $K^{X}(t)$ ).

In the process of solving the task, instead of the consequence of management vectors $U\left(t_{1}\right), U\left(t_{2}\right), \ldots, U\left(t_{T}\right)$, we will use the management matrix $U$ with dimensionality $r \times T$, where $r$ is the dimensionality of the combined management vector $U(t)$ and $T$ is the quantity of points on the management interval. Correspondingly, instead of the consequence $K\left(t_{1}\right), K\left(t_{2}\right), \ldots, K\left(t_{T}\right)$, we will use the correction matrix $K$ with dimensionality $r \times T$.

The algorithm of the calculation involves the following steps:

Initial conditions. Iteration ${ }^{j=0}$. Scenario writer (Figure 1) forms the initial approximation of the management matrix $U^{(0)}$ for the whole horizon of management:

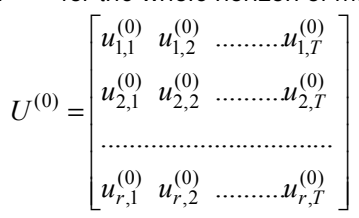

Coefficients of the general correction matrix ${ }^{K^{(0)}}=\left\|k_{i, j}^{(0)}\right\|_{r \times T}$ have the initial value of $1: k_{i, j}^{(0)}=1, \forall i, j$.

Stage 1. We solve the direct task of forecasting (17) - (20) for scenario $U^{(j)}$ and calculate coefficients of the matrix $Q^{(j)}=\left\|q_{n, k}^{(j)}\right\|_{N \times T}$ of the relative deviation of the current values of the target indicators ${ }_{S, 1}\left(U^{(j)}, t_{k}\right),{ }_{S, 2}\left(U^{(j)}, t_{k}\right), \ldots$, $z_{S, N}\left(U^{(j)}, t_{k}\right)$ from the target trajectories $z_{S, 1}^{0}\left(t_{k}\right), z_{S, 2}^{0}\left(t_{k}\right), \ldots, z_{S, N}^{0}\left(t_{k}\right)$ in all points of the horizon of forecasting $t_{k}=t_{1}, t_{2}, \ldots, t_{T}$ :

$$
q_{n, k}^{(j)}=\left|\frac{z_{n}\left(U^{(j)}, t_{k}\right)}{z_{n}^{0}\left(t_{k}\right)}-1\right| .
$$

The current value of the criterion "dissatisfaction" is calculated:

$$
\Phi^{(j)}=\sum_{n=1}^{N}\left\{g_{n} \sum_{k=1}^{T} q_{n, k}^{(j)}\right\} \text {. }
$$

If $\Phi^{(j)}-\Phi^{(j-1)}<\varepsilon_{0}$, the calculation stops and the matrix of management $U^{(j)}$ is a solution to the multipurpose task (21), (17) - (20), in other case we transit to the stage 2 . Here $\varepsilon_{0}$ is a small number, for example, 0,05 .

Stage 2. Iteration $j:=j+1$.

The coefficients of the correction matrix are refined: $K^{(j)}=f_{K}\left(K^{(j-1)}, Q^{(j-1)}\right)$.

Stage 3. Management matrix is refined: $U^{(j)}=U^{(0)} \otimes K^{(j)}$.

The transition to the first stage is made.

The process of solving the task includes 150-200 iterations, which is much faster than in the well-known GEMPACK (Harrison V., Pearson K., 2000) and GAMS (Rutherford T., 1997) packages.

The developed matrix method of search is suitable for solving the following tasks of multipurpose management (21):

1. Evaluation of attainability of target reference points for dozens of goals, hundreds of managing variables and deep horizons of forecasting.

2. Verification and correction of reporting data for the elimination of their inner contradictions (misbalance).

3. Calibration of the model of the region for the reproduction of trajectories of the reporting period.

4. Ensuring of the long-term dynamic equilibrium on the modeled markets of goods and services in the tasks of macroeconomic modeling (task (19)-(20)).

2. Solution of systems of nonlinear algebraic equations.

High speed and accuracy of the method is achieved at the account of the following factors:

- Simultaneous movement on the all $r \times T$ control variables (24); 
- The use of the multiplier increment step of managing variables (27) instead of the additive one. The complexity of the search matrix method $W \sim N \times r^{2} \times T$.

In conclusion it must be noted that the developed software for regional development modeling and strategizing (Figure 1) can be represented as three put-in outlines of optimization tasks (Figure 5) combined together into a single unit through the management parameters vectors' components with the same name $U=\left[U^{\text {exo }}, U^{\text {end }}\right]$.

The outline of strategic management (the outer one) is made by the tasks of evaluating attainability of strategic objectives when the best exogenous scenario minimizing the general "dissatisfaction" from failure to reach the strategic goals is selected. The second outline is formed by the models of purposeful activity of the economic agents optimizing their utility functions on the basis of the current exogenous scenario and corrective action of the agent "invisible hand of the market" which solves its tasks in the third outline minimizing material and value misbalances between supply and demand on the markets for conventional products. The developed universal solver allows to solve the whole system of the tasks of modeling and strategizing.

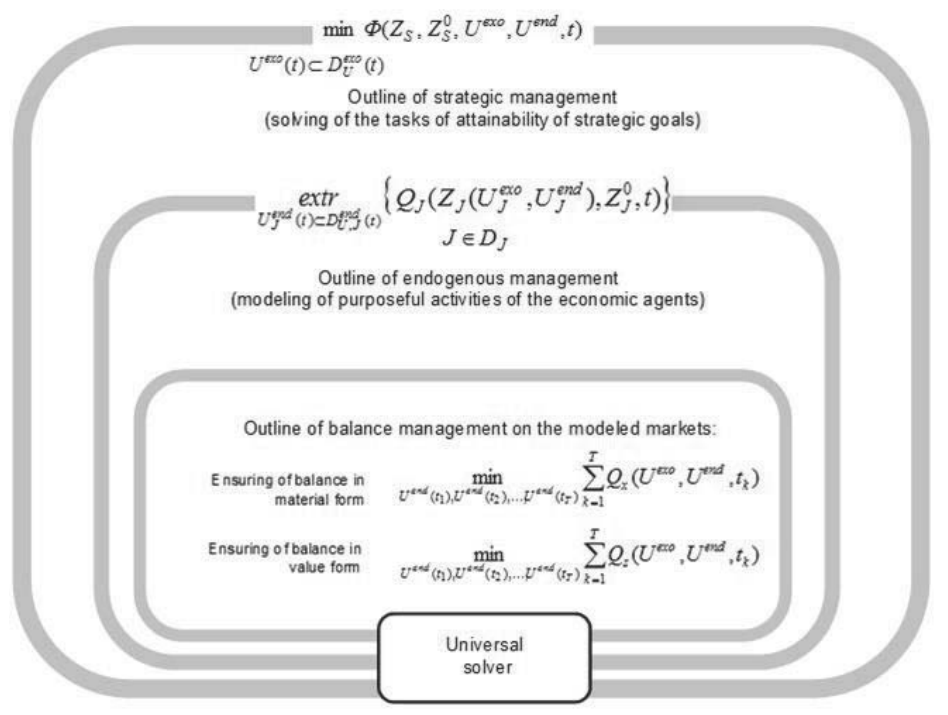

Figure 5. Outlines of Multipurpose Management

\section{Discussion}

The task of multipurpose management in the formulation (21) is rather a general one. For example, it subsumes the task of ensuring of balance of supply and demand on the product markets (where the goals are zero misbalances; the managing parameters are values of supply and demand of the economic agents). It also includes the task of solving the systems of equations (where the goals are the values of the free members of equations; the managing parameters are unknown variables in equations). Even optimization tasks can be reduced to the task of multipurpose management if we set wittingly high (maximization case) or wittingly law (minimization case) goals. Universality of the problem (21) made it possible to bring together within a single computing process modeling activities of the economic agents and the external management aimed at achieving strategic goals. Universal solver that implements matrix method of search (22) - (27) in conjunction with the objectives of maintaining the equilibrium of supply and demand on the product markets and optimization of utility functions of the economic agents solves the problem of evaluation of attainability of the strategic goals (see. Fig. 5). That is, the search is conducted simultaneously on all the components of the management vector. This "simultaneity" significantly reduces the amount of computation and gives high-quality results.

An important advantage of the developed tools is the possibility to solve the problem of dynamic equilibrium both in value (19) and in material (20) form. The product-sector balance, used in modeling, considers the balance on the markets up to the increase in reserves (see (13) (15)). The situation with zero growth in reserves corresponds to the 
neoclassical approach but is far from the real economy. Regional statistics show that the stable economic growth of the annual increase in material resources and finished products fluctuates in the range of $-3 \%,+3 \%$. That is, it makes no sense to solve problems of supply and demand "up to zero". By controlling the growth of reserves in the equations (13) and (15), we can simulate any non-equilibrium situations in the real economy. The only thing is that we have to decide what goals to set in the tasks (19) and (20) instead of zero.

In the proposed model of the subject of the Russian Federation, the economy is divided into 33 economic agents according to the boundaries of the sections and sub-sections of the Russian OKVED. The model uses the following aggregated conventional products: intermediate goods and services; investment products and services; consumer goods and services; government services; labor services. Such level of aggregation is explained by the needs of regional forecasting as well as availability of detailed regional statistics. There are no methodological limitations on further decomposition of the economic activities and conventional products. Thus the developed model of the Russian economy uses 45 types of economic activities (agents) and 15 aggregated conventional products. The model of the subject of the Russian Federation is presented in the form of matrix the columns of which form the models of economic agents (sections and subsections of the regional economy) and the rows are the system-forming models that combine the respective resources of the region into a coherent whole. This eliminates the contradiction between "particular" (models of individual economic agents) and "general" (models of regional resources as a whole, for example, financial, labor resources).

The material for forming the information base of the developed model of the subject of the Russian Federation is publicly available regional statistics and reports of various regional ministries and departments. To complement temporarily missing data and eliminate imbalances, we developed the means of verification and correction of officially published data. To adjust the calibration coefficients of the model, we used calibration for the base year, i.e., selection of values of the calibration coefficients of the model at which the model most accurately reproduces historical data of the national accounts of the base year and the expected response to external test stimuli in accordance with chosen theoretical assumptions. These tools allow to customize the model to suit every subject of the Russian Federation. It is also worth noting that the task of correction (balancing) of the officially published data and the task of setting the coefficients of the model fall into the class of tasks of evaluation of attainability of the stated goals and is solved with the help of the developed matrix method of search (22) - (27).

The created methods, models and information technologies of the region's strategy development have been successfully tested when elaborating the strategies of Altai Krai and Krasnoyarsk Krai. The main components of these technologies formed the basis of creation of a series of automated systems and complexes which are used in a number of subjects of the Russian Federation, in particular in the governments of St. Petersburg, Komi Republic, Altai Krai, Krasnoyarsk Krai and Samara Oblast (Tsybatov, Pavlov, 2014). These systems are also used in the projects of National Research University Higher School of Economics and Federal State Budgetary Educational Institution of Higher Professional Education Northern (Arctic) Federal University named after M. V. Lomonosov.

\section{Gratitude}

The author of the article used the results of research conducted within the framework of the project "Development of Technology for Identifying Crisis Situations and Ways of their Solution. Creation of the Model of Advanced Strategic Management" with the financial support of the Ministry of Education and Science of the Russian Federation (agreement № 02.G25.31.0023).

\section{References}

Bahtizin A.R. Agent-oriented Models of Economy. M.:Economy, 2008. - p.279

Volkov E.A.Numerical Methods. M.:Physmatlit, 2003.

Gill F., Murrey U., Right M. Practical Optimization. Translation from English - M.:Mir, 1985.

Makarov V.L. Calculated Model of the Russian Economy // CEMI RAN, 1999, Preprint, number 99.

Makarov V.L., Bahtizin A.R., Sulakshin S.S. The Use of the Calculated Models in the State Management. M.:Scientific Expert, 2007.

Methodological Provisions on Statistics. №. 1 / The Russian State Committee of Statistics. - M., 1996. - p.674

Methodological Provisions on Statistics. № 5. / The Russian State Committee of Statistics. - M., 2006. - p.510

Novikov D.A., Chhartishvili A.G. Active Forecasting. M.:IPU RAN, 2002. - p.101

The System of National Accounts 2008. ledited by the Professor Ivanov Y.N., -New-York, 2012.

Tsybatov V.A. (2013). The Principles of Construction of Macroeconomic Models / Economy, Modeling, Forecasting. Minsk: Scientific Research Economics Institute of the Ministry of Economy of the Belarus Republic. - 2013,p. 84-94. 
Tsybatov V.A., Pavlov L.P. (2014) The Experience of Use of the Technology of Estimation of the Target Reference Points in the Tasks of Strategic Planning. / Kazan Bulletin on Economics. - 2014. - № 3, p. 11-18.

Federal law from 28.06.2014 № 172-\$3 "On the Strategic Planning in the Russian Federation». Electronic resource http://base.garant.ru/70684666/

Dixon Peter and Maureen Rimmer (2002). Dynamic General Equilibrium Modeling for Forecasting and Policy: a Practical Guide and Documentation of MONASH, North Holland.

Feltenstein A., Shah A. (1995). General Equilibrium Effects of Investment Incentives in Mexico, Journal of Economics Development 46: 253-269.

Harrison V., Pearson K. (2000): An Introduction to GEMPACK. Fifth edition/ Melbourne. Australia. Center of Policy Studies and Impact Projects.

Markusen J., Rutherford T. and Hunter L. (1995). Trade Liberalization in a Multinational-dominated Industry. Journal of International Economics 38: 95-117.

Pospelov I.G. Economic Agents and Systems of Balances: Working paper WP2/2001/03, Moscow: State University - Higher School of Economics, 2001, $68 \mathrm{p}$.

Pyatt, G. and J. I. Round (1985). Social Accounting Matrices, A Basis for Planning. The World Bank, Washington, D.C., 1985

Rutherford T. (1997): Applied General Equilibrium Modeling with MPSGE as a GAMS Subsystem: An Overview of the Modeling Framework and Syntax. Department of Economics. University of Colorado.

Taylor L. (1990). Socially Relevant Policy Analysis: Structuralist Computable General Equilibrium Models for the Developing World, MIT press, Cambridge (MA).

Wickens M. Macroeconomic Theory: A Dynamic General Equilibrium Approach. Princeton: Princeton University Press, 2008. 